\title{
DEL GRIEGO ACTUAL AL CLÁSICO: LA EXPRESIÓN ORAL
}

\author{
Ismael Enrique Correa Morales \\ Universidad de La Laguna
}

\section{RESUMEN}

Este es un trabajo que aúna la investigación histórica y la lingüística con una neta intención pedagógica. Primero, se centra en la transformación que la forma más clásica de la lengua griega sufrió a partir del humanismo europeo y que ha comprometido su supervivencia en las instituciones educativas, como demuestra el estado agonizante que se palpa hoy en día tanto en los centros de enseńanza secundaria como en las universidades. A continuación, trata de ofrecer un nuevo fundamento metodológico, competente y legítimo, en base tanto a la diferenciación lingüística propuesta por F. de Saussure a inicios del siglo XIX acerca de qué es lengua y qué es habla en la práctica didáctica como a la aceptación de una nueva pronunciación aplicada a sus fases más antiguas: tomando como premisa que la lengua griega es única e indivisible, nos proponemos que la pronunciación de la forma actual de la lengua griega opere como órgano vital y guíe el ejercicio de la enseñanza de nuestro legado antiguo mediante su más pura manifestación lingüística.

PALABRAs ClAVE: oralidad, pronunciación, escritura, griego antiguo, griego moderno.

FROM THE CURRENT GREEK TO THE CLASSIC:

ORAL EXPRESSION

\section{Abstract}

This is a work that combines historical and linguistic research with a clear pedagogical intention. Firstly, it focuses on the transformation that the most classical form of the Greek language underwent from European humanism and that has compromised its survival in educational institutions, as the agonizing state that is felt today in both secondary schools and universities. Secondly, it tries to offer a new methodological, competent and legitimate foundation, based on both the linguistic differentiation proposed by F. de Saussure at the beginning of the 19th century about what is langue and what is parole in didactic practice, as well as acceptance of a new pronunciation applied to its oldest phases: taking as a premise that the Greek language is unique and indivisible, we propose that the pronunciation of the current form of the Greek language operates as a vital organ and guide the exercise of our teaching ancient legacy through its purest linguistic manifestation.

Keywords: orality, pronunciation, writing, Ancient Greek, Modern Greek. 
Je ne croy pas qu'il y ait personne qui ne voye quelle misère c'est de ne rien comprendre en cette Langue que par les yeux ${ }^{1}$.

Las lenguas no sólo se pueden llamar muertas cuando no existe pueblo alguno que las hable.

Los que las reciben por los ojos, y por el inanimado intermediario del papel se hallan en el caso de los que sólo conocen a una persona por medio de su retrato.

Sólo una larga residencia en el país cuya lengua aprendemos puede darnos

la llave maestra del corazón de sus habitantes: cien mil recuerdos deben despertarse al oír ciertas palabras, si es que hemos de penetrar completamente el sentido de un escritor, de un verdadero poeta que supo usarlas.

(Blanco-White) $^{2}$

\section{INTRODUCCIÓN}

Este artículo de investigación se centra en el íntimo deseo de encontrar y consolidar una salida a la problemática de una enseñanza metodológica, práctica y amena del griego clásico, una lengua que se distingue especialmente por el alto grado de dificultad que presenta su enseñanza y aprendizaje. Todos somos conscientes del lúgubre panorama por el que está atravesando en la enseñanza secundaria y superior; hoy, la apreciación en torno a la lengua griega solo alcanza a la evocación de un lejano y exiguo reflejo de los frutos que empezó a engendrar hace más de tres milenios, hasta tal punto que sus residuos asoman distorsionados como una refracción segmentada y desmembrada de lo que existió, y que ha derivado en una sombra socavada y sometida a lo antiguo, viejo y desgastado.

Sin embargo, quien se haya concedido la oportunidad de vivir una temporada en Grecia percibe que el idioma que se usa como vehículo de expresión hoy en día está también íntimamente ligado al que existió en la Antigüedad hasta tal punto que se vislumbra que la lengua griega ha sido y sigue siendo una, única e indivisible (ver anexo). Al contrario del latín, que se desglosó en lenguas romances como el italiano, francés y español, el griego actual se identifica por seguir siendo una forma de la misma lengua milenaria que perdura en su propio territorio, natural y natal. Una

${ }^{1}$ Extraído del lema del acreditado libro de Allen (1991, p. 1) sobre la pronunciación del griego clásico, quien a su vez remanda a C. Lancelot, Nouvelle Méthode pour apprendre facilement la Langue Grecque, Paris 1819.

2 Extraído del libro de Ruiz Casanova (2018) sobre la historia de la traducción. 
continuidad caracterizada por su intenso carácter dialectológico y polimorfo, aunque hoy en día las variedades lingüísticas se reducen a idiomatismos regionales, pero con los que subsiste y cohabita todavía una inmensa plétora de rasgos arcaizantes.

Partiendo de la premisa de que el griego antiguo y el moderno son una misma lengua, esta visión lingüística de personalidad unitaria nos proporciona una herramienta y vínculo fundamental para su estudio. Hemos de aprovechar su vitalidad secular para proyectarnos hacia su pasado; así lo concibieron los humanistas italianos y primeros helenistas modernos, quienes estudiaron griego antiguo en Constantinopla e Italia, inmersos en el mundo tardobizantino de la época. Su legitimidad histórica y vitalidad vigente son factores que revierten decisivamente en que el empleo del griego actual sigue cumpliendo con los requisitos y pautas pedagógicos precisos para el aprendizaje del griego antiguo.

Nuestra propuesta de investigación aspira a resaltar y contextualizar las consecuencias nefastas de las mutaciones lingüísticas (sobre todo la relacionada con la pronunciación) artificiales que sufrió el griego cuando empezó a enseñarse en Europa a partir del Humanismo, en correspondencia temporal con la toma de Constantinopla en 1453 por el Imperio otomano.

La figura polifacética y preponderante del Humanismo europeo, Erasmo de Rotterdam, también se dedicó al estudio de la lengua griega: como señal de su amor por esta lengua cambió su propio nombre haciéndolo descender del adjetivo

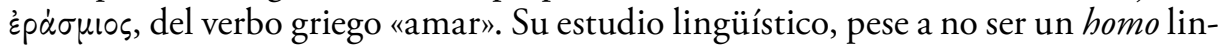
güista (obviamente, la lingüística histórica o comparativa como disciplina científica autónoma aún no existía), que había llevado a cabo en 1528, apuntaba a indagar cuál era la pronunciación real del griego en el siglo $v$ a.C., aunque su objetivo final no apuntó nunca a implantar sus resultados en la didáctica de la lengua, para cuya función él mismo declaraba abiertamente el requerimiento imprescindible de la presencia de un nativo en las universidades europeas. La implantación de la pronunciación restituida erasmiana disfrutó de un auge paralelo al del establecimiento de las reformas luteranas en Alemania e Inglaterra, y de la férrea oposición de los principados alemanes y la corona inglesa frente a la intervención unificadora de Carlos V y del papado por entonces en el corazón de Europa; a esta versión erasmiana se opuso con firmeza de argumentos, al menos durante los dos siglos y medio que procedieron (si bien las voces discordantes, como veremos, aún no se han apagado), la mayoría de los más insignes filólogos clásicos que nutrían vívidamente las instituciones educativas y de los que hemos recibido el legado más verídicamente representativo de la Antigüedad.

Nuestra propuesta trata de invocar la validez histórica y lingüística de la expresión oral connatural a la vida de toda lengua; la distinción entre escritura y lengua es de vital importancia para nuestra cuestión. Hasta ahora ha primado el estudio y la enseñanza de los elementos morfosintácticos que se derivan de la escritura del griego como hace un forense durante la disección de un cuerpo inánime, apartándose durante siglos de la materia prima para el aprendizaje de la lengua y olvidando su función primordial que, como el mismo vocablo evoca, se concretiza en su uso cuando el individuo habla, comunica, se expresa oralmente. Consecuentemente, pretendemos exponer cómo entendemos la enseñanza y aprendizaje de la 
lengua griega, para lo que, además de sus fundamentos morfosintácticos y gramaticales, es un término insalvable que prime su carácter oral. Al inicio del siglo xx, las aportaciones innovadoras por parte de F. de Saussure, fundador de la lingüística moderna, proporcionan un significado vital a lo que es realmente el lenguaje: lengua, significante, habla, y, en consecuencia, palabra, voz, expresión, distinguen y acentúan la demarcación monolítica y unilateral del estudio de la escritura, lo cual comprende una inversión de los términos hacia la experiencia de la lengua viva.

En consecuencia, nuestra propuesta metodológica se fundamentará en que la pronunciación de la lengua griega, considerada como un ente unificado e indivisible, sea la de su confluencia real, a saber, el griego actual, ya que ha derivado como resultado histórico y natural a través de su dilatado proceso evolutivo (lo contrario sería involutivo). Y este es el mayor aporte de este trabajo. Los métodos más modernos para la didáctica del griego antiguo (Assimil, Reading Greek, Athenaze, etc.) siguiendo por continuidad pedagógica el ejemplo de las estrategias metodológicas modernas de otras lenguas vivas, pese a reflejar y respetar la movilidad de la interacción dialogada, la lectura oral de los textos y asumir como punto de partida contextos situacionales más cercanos al alumno, permanecen inamovibles en la adopción reiterativa de la pronunciación desconocida, incierta, artificial y reformada del xvi. Las similitudes semánticas, de pronunciación, incluso morfosintácticas, del griego en sus diferentes etapas a lo largo de su vastísima trayectoria histórica nos evidencian que el habla del griego actual es la única opción, puesto que reúne los antecedentes y condiciones precisados para ser considerada la única pronunciación posible, por ser la actual y su última derivación sincrética y, por ende, ecuménica.

\section{FUNDAMENTACIÓN LINGÜÍSTICA}

Es un axioma decir que el lenguaje (langage o $\lambda o ́$ yos, la traducción en griego actual del término de Saussure) o facultad del ser humano para comunicarse se refleja en la interacción sistémica entre lengua (langue, $\gamma \lambda \omega \dot{\sigma} \sigma \alpha)$ y habla (parole $\mathrm{u} o \mu \iota \lambda i \alpha)$, que como medio de socialización es el rasgo más característico del ser humano que lo distingue de otras especies. Todas las especies animales poseen conductas para comunicarse, pero en ninguna de ellas podemos encontrar algo semejante al lenguaje.

La lengua está establecida por la estructura, el mecanismo, los códigos referenciales (Saussure usa la metáfora del diccionario como sinónimo de lengua para la comunidad) que los individuos reflejamos en el habla. Como parte social del lenguaje, la lengua es exterior al individuo (es supraindividual), al que no le compete ni crearla ni modificarla; es necesaria, como sistema, para que el habla se concretice, a la vez que el habla, como acto individual de voluntad e inteligencia, es imprescindible para que la lengua se realice materialmente.

Saussure, a inicios del siglo $\mathrm{xx}$, fue el primero en destacar algo que hoy en día parece obvio y que es aceptado por todos los lingüistas: el hecho de que «lengua y escritura son dos sistemas de signos distintos y que la única razón de ser del segundo es la de representar al primero" (Saussure 1945: 72). Y, por tanto, defendía la primacía de la lengua sobre la escritura, del mismo modo que históricamente el 
habla precede a la lengua. La estaticidad del registro escrito oculta con frecuencia que la lengua está siempre en evolución, más allá del control ejercido por profesores e instituciones. Sin embargo, a principios del siglo xx, en el momento en que Bally y Sechehaye editaron el Curso de lingüistica general que difundía las ideas fundamentales de la lingüística saussureana, la artificialidad científica de la pronunciación erasmiana estaba ya más que arraigada en las instituciones educativas de Europa.

Según Saussure, «el punto de partida» de los hechos de habla (o lengua oral) está en el cerebro. En su disquisición para expresar los elementos que intervienen en la comunicación refiere textualmente:

Supongamos que un concepto dado desencadena en el cerebro una imagen acústica correspondiente; éste es un fenómeno enteramente psíquico, seguido a su vez de un proceso fisiológico: el cerebro transmite a los órganos de la fonación un impulso correlativo a la imagen; luego las ondas sonoras se propagan de la boca de $\mathrm{A}$ al oído de B: un proceso puramente físico (Saussure 1945: 54-55).

Cuando uno reflexiona sobre lo escrito previamente, le viene a la mente una pregunta tanto inevitable como urgente, cuya respuesta quizás nos pudiera iluminar como si de una $\varkappa \alpha \dot{\vartheta} \alpha \rho \sigma \iota \varsigma$ reparadora se tratase: ¡está presente alguno de estos fenómenos psíquicos, fisiológicos y físicos que intervienen en el proceso oral (por ser elementos imprescindibles de nuestra facultad de usar el lenguaje) cuando enseñamos el griego clásico y lo leemos, basándonos en su escritura, según la pronunciación artificial que se le atribuyó en el Renacimiento a nuestra amada lengua griega? La respuesta parece aparatosamente negativa. Y la misma negación se refleja, a todas luces, en el trato que le hemos dado, ya que su condición moribunda es -por desgracia-celebérrima desde el siglo XIX, cuando esas mismas instituciones educativas instauraron la pronunciación erasmiana, más que una lengua, el griego clásico de nuesatra enseñanza secundaria y universitaria parece un espectro alegórico penado por su longevidad y, como Prometeo filántropo, castigado con la afonía y la inacción.

En una cita recogida por Martínez Celdrán (1996: 18)³, se dice lo siguiente: «... leer un texto quiere decir convertirlo en sonidos... La escritura nunca puede prescindir de la oralidad»: como ejemplo didáctico no debemos olvidar que la épica más antigua atribuida a Homero por la tradición se impregnó incuestionablemente de la tradición oral que los cosedores de cantos o rapsodas habían prefijado en forma y contenido.

Hablar conlleva una serie de procesos o flujos de energía, articulatorios y químicos, unos impulsos nerviosos que generan en el oyente reflejos auditivos inmediatos, bioquímicos y neurológicos, que agilizan la memoria y activan el hecho cognitivo a un nivel distintivo y superior en cuanto que se desarrolla la interrelación significativa, intrínseca (incluso psíquica) del signo lingüístico entre concepto e imagen acústica, significado y significante, que convergen y generan aquella cali-

\footnotetext{
${ }^{3}$ La cita en cuestión pertenece a W.J. Ong (1982).
} 
dad lingüística, natural y real, ausente en la MONO-TONíA de la lectura, sobre todo de la que se hace en silencio vuelta y cerrada hacia uno mismo. Hay, pues, en la lengua, como en la música, una base material, un vehículo que transmite el mensaje: el sonido (Luque Moreno 2014: 11).

Precisamente Gardner (20173: 150), en su acreditado libro sobre las múltiples inteligencias, menciona que ya Sócrates había reconocido y precisado la inteligencia musical de la lengua para relacionar «los modos específicos y rasgos distintivos de carácter humano al asociar los modos jónico y lidio con la indolencia y la molicie, y los modos dórico y frigio con el valor y la determinación». Incluso conjetura Gadner $\left(2017^{3}\right.$ : 161) la idea de que la expresión y la comunicación lingüísticas y musicales han brotado de una raíz común: ¿cómo negar al habla el tono, su ritmo y timbre?

Pero vayamos al centro del cuestionamiento que realmente nos interesa. Situemos la lengua en otro contexto diferente: como objeto de una metodología pedagógica o el aprendizaje de un sistema lingüístico nuevo. El hecho de que la lengua (en condiciones vitales normales) sea un sistema de carácter social e inmutable, ya que es el «diccionario» del que los hablantes se sirven para comunicarse, pone de manifiesto que la colectividad lingüística está permeada desde su nacimiento por dicho sistema, pues nació en medio de un contexto temporal, geográfico y lingüístico bien definido que lo determina y forma. No obstante, este marco natural está ausente en el proceso de aprendizaje del griego antiguo, que, como sistema supraindividual, resulta desconocido al estudiante neófito o aprendiz. Y es aquí donde está la disyuntiva, ¿empezamos con el aprendizaje desde la lengua hacia el habla o, inversamente, desde el habla hacia la lengua? ¿ Nos embarcamos en una labor analítica o constructiva? Según la metodología deductiva empezaríamos por la abstracción del sistema lingüístico hacia lo concreto, pero según la inducción empezaríamos por lo concreto hacia lo abstracto.

Cuando un estudiante se enfrenta al aprendizaje de una lengua extranjera, ¿qué tiene en mente, qué sabe de ella?, ¿¿lo abstracto o lo concreto?, ¿ ¿tiene conciencia de la abstracción del sistema o ha escuchado su materia fónica? La lengua es necesaria para que el habla sea inteligible, pero el habla es necesaria para que se establezca la lengua. Históricamente, el habla precede siempre: el habla, como elemento agente en un acto de comunicación y expresión de lo concreto, constituye la forma primera del proceso. Paulatinamente, los hechos de habla y los cambios originados e incrementados por los individuos o el colectivo, repetidos y aceptados por la comunidad, son los que van conformando la lengua, la entidad abstracta.

El desconcierto o confusión se produce al aplicar las conclusiones de hechos de lengua al habla, en el contexto del estudio de la lingüística diacrónica o comparativa, ya que esta, por tener como objeto un hecho histórico lejano, se dedica a la evolución de elementos parciales e inconclusos que No se pueden usar legítimamente en el nivel más concreto del lenguaje, el habla. Y he aquí que nos damos cuenta de una realidad que fácilmente se escapa: que Erasmo, en su estudio sobre la pronunciación del griego, (inconscientemente) se refería al nivel de lengua y no se refería al habla, hecho este del que él era consciente, pues no solo nunca puso en práctica como profesor en Lovaina u Oxford las conclusiones de su estudio, sino que aconse- 
jaba (como veremos en el próximo apartado) la intermediación de un griego nativo para que se aprendiera la pronunciación genuina del habla griega. El uso, en este caso abusivo, del término lengua es consecuencia de que entonces, a partir del siglo XVI hasta inicios del siglo xx, no se empleaba la oposición entre lengua y habla, distinción fundamental que aún hoy se sigue desatendiendo.

Por lo tanto, el aprendizaje de un idioma extranjero se ha de fundamentar priorizando el habla, es decir, su oralidad o pronunciación, que describiríamos como la envoltura personal del sonido físico o significante. El hablante que se sirve de la facultad del lenguaje para comunicarse no puede sino adoptar la forma lingüística que está en curso, que en nuestro caso es la del griego actual.

Como contrapunto y coherencia con lo referido previamente, el profesor o estudioso de la forma clásica del griego tiene el espacio o la opción de puntualizar, en el marco abstracto de la lengua, el valor exacto de un fonema o de su aparato fonológico desde el punto de vista de la lingüística sincrónica ${ }^{4}$, con el objetivo de evidenciar posibles relaciones u oposiciones en el interior del sistema, o desde la diacronía, si lo que pretende es poner de manifiesto la senda evolutiva de la lengua.

Hemos de concluir e insistir en que nuestro proyecto educativo defiende que los argumentos pedagógicos tienen que prevalecer sobre los estrictamente histórico-filológicos o, dicho de otro modo, que los argumentos histórico-filológicos no pueden esgrimirse para desacreditar el empleo de la pronunciación actual del griego, sobre todo hoy en día a la luz de los métodos más modernos y vanguardistas que se usan en el proceso de enseńanza/aprendizaje.

\section{FUNDAMENTACIÓN HISTÓRICA}

Somos conscientes de la diversidad dialectal y, por ende, del aspecto polimorfo de la lengua griega, en cuanto que la forma jónico-eolia de Homero es distinta del jónico-ático de los escritores del siglo v a.C. Pero a partir del 403 a.C., bajo el arcontado de Euclides de Atenas, se acelera en el seno del mundo griego, entonces compuesto por ciudades-estado, una tendencia irreversible hacia la unificación de la expresión lingüística escrita, que se reafirma bajo la égida política de carácter hegemónico del rey macedonio Filipo II y de su hijo Alejandro III. Durante el período siguiente, en época helenística, se generaliza una única forma escrita derivada del ático y el aticismo, usualmente llamada lengua común o, simplemente, koiné, tomando como préstamo el adjetivo del sintagma griego original ( convirtiéndolo en un término (Browning 1982: 44-52).

Como ya he referido al respecto en otro artículo mío (Correa 2017-2018: 49):

\footnotetext{
${ }^{4}$ Saussure prefería el término idiosincrónico en cuanto que puntualizaba con mayor precisión el contexto temporal objeto de estudio.
} 
El término koเvท่, que significa 'común', fue originariamente ideado por los gramáticos alejandrinos del in siglo d.C., tales como Apolonio el Díscolo y su hijo Elio Herodiano, para definir esta lengua hablada como producto de la confluencia de los cuatro dialectos «comunes» que conformaban toda la cultura griega de la Antigüedad, puesto que era la forma normalizada para el registro escrito del helenismo.

Desde entonces, el resultado de las prescripciones de los gramáticos aticistas dio lugar a una derivación «biformal» de la lengua griega, a dos formas paralelas (y no una diglosia o bilingüismo, pues la lengua siguió siendo siempre una, la griega): un registro culto escrito y otro hablado por el vulgo.

Con el devenir de los siglos, en la Grecia moderna se entabló una disputa lingüística tendente a hacer predominar, en lo referente al registro escrito y menos al oral, la hegemonía ya de aquella forma culta, ya de la otra vulgar, a saber, de la $\kappa \alpha \theta \alpha \rho \varepsilon \dot{0} \sim \sigma \alpha$ (katharévusa o 'depurada', llamada también pura o conservadora) o de la $\delta \eta \mu о \tau \iota \kappa \dot{~(d e m o ́ t i c a ~ o ~ p o p u l a r, ~ o ~ s e a, ~ l a ~ q u e ~ e s t a b a ~ e n ~ c u r s o) . ~ E s t a ~ c u e s t i o ́ n ~ l i n-~}$ güística se polarizó hasta llegar a transformarse en una belicosa cuestión extralingüística durante los siglos XIX al xx a partir de la independencia de la nueva nación helénica, pero la balanza fue inclinándose paulatinamente hacia la forma hablada, la más natural, hasta que se impuso en el último cuarto del siglo pasado mediante la ley 309/1976 (Мпампілі 2 тнг 20025: 204; Correa 2017-2018: 55).

No obstante, más allá de las diferencias morfosintácticas y las razones sociales en favor de la hegemonía de una u otra forma de la lengua griega, la pronunciación siempre permaneció única e inalterable, siempre estuvo fuera de discusión. Esta fue una discusión que se planteó en Europa en plena época humanista-renacentista, en 1528, cuando Erasmo de Rotterdam publicó en Basilea su De recta Latini Graecique sermonis pronuntiatione dialogus ${ }^{5}$, en el que proponía un nuevo modo de pronunciar la forma escrita del griego antiguo y del latín. Pese a que durante los dos siglos que siguieron, la inmensa mayoría de los eruditos de estudios clásicos se opusieron, desde principios del siglo XIX en adelante esta propuesta se ha erguido victoriosa en toda Europa, excepto en Grecia y Chipre, los herederos más directos del helenismo. Como ya mencionamos en nuestro apartado de Justificación Lingüística, ello se debe a que, en aquel entonces, no había nacido todavía la lingüística como disciplina científica que estudia las lenguas: por aquel entonces solo existía un acercamiento intuitivo. Ulteriormente, cuando a principios del siglo XIX nació la lingüística histórica ${ }^{6}$, la pronunciación artificial erasmiana ya estaba firmemente enraizada en las instituciones educativas.

Nuestra investigación y propuesta innovadora se centra en torno a la invención de la tesis erasmiana y las consecuencias demoledoras que acarreó su interven-

one_1643.

${ }^{5}$ Cf. https://la.wikisource.org/wiki/De_recta_latini_graecique_sermonis_pronuntiati-

Como sabemos, la fecha de fundación de la lingüística histórico-comparada es 1816, año en que Franz Bopp publica Sobre el sistema de conjugación de la lengua sánscrita, comparado con el de las lenguas griega, latina, persa y germánica. 
ción, la cual, según nuestra opinión, asestó un golpe mortal a la lengua griega, hasta el punto de que hoy se la considere una «lengua muerta», cosa que en absoluto es cierta y se opone totalmente a lo que fue y sigue siendo: una lengua culta, viva y sabia.

Con el fin de ser objetivos y coherentes en nuestra investigación, empezaremos por exponer las vicisitudes que acompańaron la propuesta, originariamente bien intencionada, de Erasmo. Ante todo, hay que plantearse varias preguntas al respecto: ¿cuál era la pronunciación del griego hasta el momento en que Erasmo publica su diálogo? ¿Cuál fue la reacción de los eruditos coetáneos? ¿Qué pensaba el mismo Erasmo sobre su tesis? ¿Por qué llegó a prevalecer la pronunciación científica o erasmiana en la Europa occidental? Nuestras respuestas contextualizadas a estas preguntas allanarán el camino y facilitarán el método a una propuesta innovadora, que comprenderá la parte fundamental de nuestra tesis. A la tesis erasmiana se opondrá una antítesis, la cual generará una síntesis que no es otra que la de adoptar la pronunciación del griego actual como la vía más natural de pronunciar la lengua griega, ya corresponda a la época arcaica, ya a la época clásica, ya a la helenística o a la bizantina. A esta forma se la llama convencionalmente pronunciación histórica o nacional, aunque nosotros preferimos definirla como pronunciación natural debido a su natural evolución.

Pero vayamos por partes.

Como es sabido, hasta el siglo xv la única pronunciación existente era aquella en uso por los griegos bizantinos. Tras la caída de Roma en el 476 d.C., el griego casi desapareció en Occidente durante casi mil años ${ }^{7}$, pero seguía siendo la lengua oficial de Bizancio, donde, fuera de la liturgia estatal, en que predominaba la lengua conservadora aticista, predominaba el habla popular, la $\delta \eta \mu \propto \tau \kappa \dot{\eta}$. El nacimiento del renacimiento humanista y el helenismo se focaliza, inicialmente, en Italia entre Florencia, Venecia y Roma, donde academias particulares y universidades emprendieron la labor de recuperación de la Antigüedad griega. Antes de la caída de Constantinopla en 1453 y la consecuente llegada masiva de eruditos griegos a la península itálica, hubo personajes como Leoncio Pilato ${ }^{8}$, quien, a instancias de Giovanni Boccaccio en 1360, asumía la primera cátedra de Griego en Florencia, siendo así el primero en desempeñar la enseñanza del Griego a nivel universitario en Europa. En este punto hay que precisar que desde la Antigüedad tardía la lengua griega se había enseñado sin interrupción en los monasterios de las comunidades ítalo-helénicas del sur de Italia y Sicilia, cuya metodología se basaba en las prácticas y pronunciación bizantinas: entre los manuales en uso estaban los diccionarios de

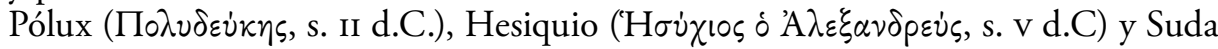

${ }^{7}$ A finales del Trecento, Leonardo Bruni, un alumno de Manuel Crisoloras (Mavoùं $\lambda$ $\mathrm{X} \rho v \sigma 0 \lambda \omega \rho \tilde{\alpha} \varsigma)$ en la Universidad de Florencia y luego importante traductor de obras de Platón, Aristóteles y Plutarco, escribía: «Nadie, durante setecientos años ha dominado en Italia las letras griegas; y sin embargo reconocemos que de ellas viene toda la ciencia» (apud Lafaye 2005: 71).

${ }^{8}$ Monje calabrés, discípulo de Barlaam de Seminara, que vivió años en Creta y Constantinopla. La influencia griega en Calabria, Apulia y Sicilia, regiones importantes de la antigua Magna Grecia, se mantiene, aunque mínimamente, hasta hoy en día. 
(

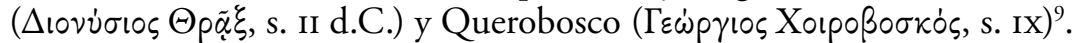

Otro docto bizantino muy importante fue el ya citado Manuel Crisoloras (1355-1415), embajador bizantino en Venecia y luego, en 1396, profesor de Gramática Griega en la Universidad de Florencia, ciudad en la que Cosme dei Medici funda en 1438 la Academia Platónica, a instancias del platónico bizantino Pletón Gemistós ( $\Pi \lambda \dot{\eta} \theta \omega \nu \Gamma \varepsilon \mu \iota \tau \tau$ ós, 1355-1452), que contaba con una inmensa colección de manuscritos en griego y que fue refundada por Lorenzo dei Medici, conocido como el Magnífico, en 1462 con la aportación de humanistas de la talla de Marsilio Ficino y el Pico de la Mirandola (Lafaye 2005: 70-71 y 240-241; Signes Codoñer 2003).

También en Venecia se formó una Academia «informal» en torno a la célebre imprenta de Aldo Manucio (la imprenta aldina, creadora del libro de bolsillo), en su propia villa de San Agostino, dependiente de la Universidad de Padua (que estaba a unos $30 \mathrm{~km}$ ), dedicada casi exclusivamente a la publicación de textos griegos.

Por último, en Roma, la llegada al papado de León X, hijo de Lorenzo dei Medici, en 1513 supuso, según Lafaye (2005: 76-77), el mecenazgo "cultural y artístico más pródigo de la época», dedicando una febril labor a la difusión del Griego: precisamente con el propósito de "mejorar el acento de los estudiantes romanos», León X puso a Marcos Musuros (Mápros Movбoúpos, 1470-1517) al frente del Colegio griego (la llamada Academia Medicea).

En torno a estos tres focos (Florencia, Venecia-Padua y Roma) de transmisión de la lengua y cultura griega giraban los profesores, gramáticos y humanistas

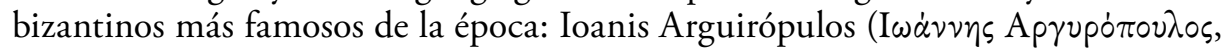

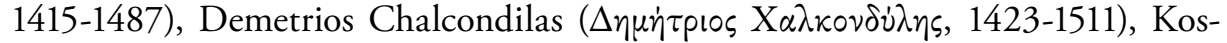

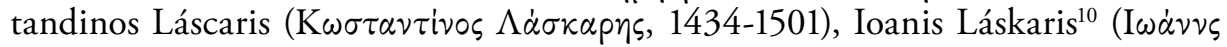

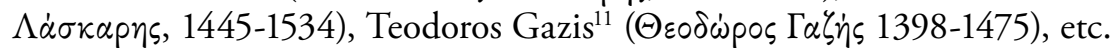

En este círculo se instruyó también Geert Geertsen, o sea, Desiderius Erasmus van Rotterdam o Roterodamus, cuyo fervor y dedicación al resurgente Humanismo lo indujo a cambiar su nombre por los del latino Desiderius y su sinónimo

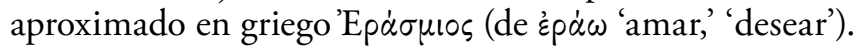

Erasmus había aprendido griego en los Países Bajos, París, Londres y Oxford, pero sobre todo hablándolo en Venecia durante los años 1506-1509 en el círculo de los ilustres humanistas helenos que se había reunido en torno al impresor Aldo

9 Cf. Rotolo (2002: 927), quien agrega que el griego se enseñó sin interrupción en los monasterios de las comunidades ítalo-helénicas del sur de Italia. Sobre toda esta cuestión de la emigración de sabios bizantinos a Italia, vid. también Signes Codoñer (2003).

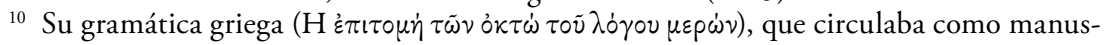
crito desde 1460, fue la primera en imprimirse en Occidente: en 1476.

11 Después del Epitome de Láscaris, la Gramática de Teodoro de Gaza, en cuatro volúmenes, fue la segunda gramática griega que se imprimió en Occidente: en 1496. 
Manucio $^{12}$, quien -entre otras normas de igual severidad- prohibía que se hablara en otra lengua que no fuera el griego so pena de sufrir multas pecuniarias a quien infringiera esta norma (aunque no se imponía multa a los errores, Lafaye 2005: 243): el dinero servía para organizar los banquetes al modo antiguo según la descripción platónica (ПетPOYNIA $2002^{2} \beta$ : 987).

La metodología que empleaban los humanistas (también los monasterios del sur de Italia) para aprender griego se regía siempre por la forma lingüística contemporánea, o sea, la bizantina: empezaban por conversaciones sencillas en la lengua cotidiana, seguían con el aprendizaje de la lengua culta contemporánea y los textos evangélicos, y acababan con la lectura de los grandes clásicos de la Antigüe$\mathrm{dad}^{13}$. Que el método era la conversación en la lengua viva contemporánea lo atestiguaba también, en el siglo xIX, Evangelinos Apostolides Sofocles, un ilustrísimo filólogo de la Universidad de Harvard (apud Tovar 1990: 356):

Lo natural, pues, es que quien desee leer la forma antigua comience por leer y hablar la moderna, como se hace en todas las lenguas vivas y era lo normal en el Renacimiento, cuyos frutos en los estudios clásicos no necesitan comentarios adicionales.

El mismo san Agustín decía en sus Confesiones (Libro 1, cap. XIV) que odiaba el griego y amaba el latín porque lo obligaban y castigaban para asimilar de memoria la primera lengua, mientras que el latín

... lo aprendí, digo, sin el grave apremio del castigo, acuciado únicamente por mi corazón, que me apremiaba a dar a luz sus conceptos, y no hallaba otro camino que aprendiendo algunas palabras, no de los que las enseńaban, sino de los que hablaban, en cuyos oídos iba yo depositando cuanto sentía.

Está claro que no hay método mejor para aprender una lengua que estudiarla y practicarla diariamente en su contexto vivo.

Una nota curiosa, pero que también marca la impronta de lo que el mismo Erasmo pensaba sobre cuál era el método adecuado que se debía seguir para aprender una lengua, es lo que el gran humanista (Erasmi opus, epístola 2079) escribe a un joven que ha tomado la decisión de aprender francés (apud Lafaye 2005: 201):

Te portas con mucho tino, para aprender francés, a acudir a la escuela del chismorreo que es la tienda del barbero [...]. Repara, no obstante, en que una sola joven francesa te ayudará tanto como treinta hombres a aprender francés. Toma un maestro, o si prefieres una amante ${ }^{14}$.

${ }_{12}$ En la Neo akademia, según el modelo de la Academia de Platón. En este círculo se editó, en

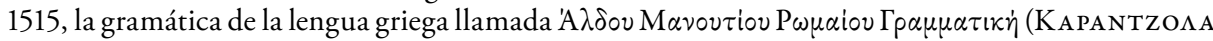
2002: 928-930).

${ }^{13}$ Cf. https://blogs.elpais.com/ayuda-al-estudiante/2013/10/la-extra\%C3\%B1a-odisea-dellatin-y-el-griego-en-secundaria.html.

${ }^{14}$ Juego de palabras intraducible entre maître y maîtresse. 
Sin embargo, el inagotable ingenio racional e indagador del sabio humanista de Rotterdam, probable e hipotéticamente llevado por comentarios de sus colegas bizantinos, durante sus tres años de estancia en el círculo aldino, sobre el posible cambio de valor de algunas letras en la antigüedad clásica (Пвтроvvias $2002^{2}$ $\beta$ : 947), lo estimularon a publicar en 1528 el célebre tratado sobre la correcta pronunciación del latín y el griego, pese a que, comprensiblemente, sabía de primera mano que las vías de aprendizaje entonces eran las que eran, bastante definidas: a través del contacto con la lengua hablada o con pequeños diálogos con una progresión temática en su desarrollo ( $\pi \rho \circ \gamma \nu \mu \nu \dot{\alpha} \sigma \mu \alpha \tau \alpha \kappa \alpha l \varepsilon p \omega \tau \dot{\eta} \mu \alpha \tau \alpha)$ (Carbonell 2010: 90, nota 5) o, quizás, con las llamadas $\sigma \chi \varepsilon \delta 10 \gamma p a \phi i \varepsilon \varsigma \circ$ Tabulae Iliacae, que eran representaciones pictóricas líticas a bajo relieve con fines educativos (Rotolo 2002: 923). Pero Erasmo, eslabón celebérrimo de esa imperecedera cadena histórica llamada cristiandad, se intuía a sí mismo como vínculo teorizante entre los asuntos mundanales y efímeros y aquellos eternamente celestes, y a fortiori asumía, por un lado, el rol de renovador espiritual (me refiero a sus críticas, entre otras, a la fastuosidad mundana de la Iglesia y a la redefinición del homo monacalis) y, por otro, el de delimitar lo profano o vulgar de lo divino; esta labor suya iba dirigida también a la regularización de las tres lenguas bíblicas, la hebrea, el latín y el griego, en sus formas de paradigma clásico y eterno; reformular a fin de restablecer lo que, por el uso del vulgo, con el tiempo estaba perdiendo su substantia prima. En esta época de humanistas, es conocida la pléyade de gramáticos reformadores del latín, los pedantes latinistas, que tildaban de defectuosos e ínfimos los escritos elaborados en alguna lengua vernácula. El Príncipe de los humanistas, otro atributo universal hacia Erasmo, detestaba hablar en su lengua materna, el flamenco, «sólo buena para perjudicar; es inútil para todos» (Erasmi opus; epístola 171); solía decir: "Asunto mío es el latín y el griego" (Lafaye 2005: 158-160).

Estamos firmemente convencidos de que la iniciativa investigadora de Erasmo en este campo de la filología distaba mucho, de pensamiento y corazón, de formar parte de algún corpus constituyente de un método de enseñanza o una estrategia pedagógica. Más bien, como hombre de letras y estudioso humanista de espíritu inquieto, propuso un constructo con el único objetivo de exponer su aportación científica de cómo era la recta pronuntiatio en el período clásico, un estudio y un empeño totalmente legítimo. ¿Qué refuerza nuestra opinión? Creemos que se deduce claramente del hecho de que él mismo, siendo profesor en la Universidad de Cambridge (entre 1511 y 1514), no solo no llegó nunca a aplicar su propuesta como materia didáctica en la conducción de sus propias clases universitarias, sino que utilizaba la gramática de Manuel Crisolorás y Teodoro de Gaza (Tovar 1990: 116; Caragounis 1997: 154) ${ }^{15}$. Además, su posición histórica está manifiesta en una carta a su colega bizantino J. Láscaris, en la que exhortaba el envío de un griego

15 Cf. también Пetpornias (2002² $\beta$ : 949), quien agrega: «Erasmo, como verdadero científico, consideraba que sus conjeturas no podían ser puntales como para no necesitar de revisiones ulteriores». 
nativo para la plaza de profesor en la Universidad de Lovaina en 1518 (apud Tovar 1990: 118 y $180-181)^{16}$ :

Pero mi opinión ha sido siempre que debiésemos enviar por un griego nativo, de quien los estudiantes puedan adquirir de inmediato la pronunciación genuina de la lengua griega; y todos concuerdan con esta opinión.

Por otra parte, Falukner (1907: 234-235), otro docto estudioso sobre este tema, añade sobre Erasmo:

Él reconoció más de una vez la validez de la pronunciación de los escolares griegos nativos, siguiéndolos en sus Coloquios y acogió enteramente el método de ellos. En todo caso, el conocimiento que él tenía del griego no era suficiente para concederse el derecho a proponer una teoría revolucionaria. Era un hombre de letras, de talento brillante, pero no era un filólogo. Varias razones contribuyeron a la victoria de su propuesta, así que, contrariamente al uso uniforme de la lengua y probablemente de su uso más coherente, la pronunciación del griego antiguo se hizo discontinua en la mayor parte del Oeste; cada país habla la legua a su manera, y a ese modo se ha reducido en mis días escolares.

\section{ALGUNOS APUNTES DE DIVERGENCIA PRIMORDIALES ENTRE EL SISTEMA ERASMIANO Y DEL GRIEGO ACTUAL}

Desde la perspectiva actual de los estudios filológicos más punteros, dedicados a discernir sobre la manera en que los griegos pronunciaban la forma preclásica y clásica de su lengua en la Antigüedad, la lingüística histórico-comparativa avala, en parte, la restitutio de la reforma erasmiana. Pero, si en líneas generales existe un consenso más o menos unitario entre los neoerasmistas, dicha reforma dista bastante, como hemos expresado en la Justificación Lingüística de nuestro trabajo, de ser una propuesta válida de lectura universal, es decir, de lectura ecuménica para el conjunto de los lectores de las múltiples naciones que componen el planeta. Las causas de ello son de variada índole, pero todas están en consonancia con la esencia de la lengua griega.

Una primera causa que origina la incertidumbre de la exacta pronunciación de los fonemas del alfabeto heleno deriva de la inexistencia de registros acústicos.

La segunda causa procede de la marcada diferenciación dialectal del griego, a lo que se añade la imposibilidad de restituir, coherentemente pronunciados, los matices fonéticos de las diversas variedades del griego.

Por último, una tercera causa reside en la imposibilidad (o la tremenda dificultad) de reflejar el cambio sufrido por los sistemas fonológicos dialectales y, por

16 Es una cita que Tovar toma de una obra de John Pickering titulada Essay on the pronunciation of the Greek Language y publicada en Cambridge en 1819. 
ende, por la pronunciación a medida que va evolucionando en sus diversas etapas históricas.

A estas causas, todas de carácter intrínseco, se añaden aquellas de carácter extrínseco íntimamente ligadas al distanciamiento temporal y espacial con nuestro objeto de estudio, pues irremediablemente, en el afán de restituir lo perdido, se ha fomentado una labor de laboratorio lingüístico, cuya faceta menos positiva ha sido la de desnaturalizar y distorsionar la esencia oral de la lengua griega.

Por nuestra parte, pese a que gran parte de la lingüística histórica moderna ha corregido y ampliado las conclusiones del humanista de Rotterdam, insistimos en seguir definiendo la pronunciación escolar como erasmiana, puesto que fue a raíz de la publicación de su Diálogo cuando se produjo la crisis y la división entre adeptos y opositores a la nueva tesis.

A continuación, expondremos algunos apuntes característicos, solo a modo introductorio y anecdótico, sobre cómo se inició y opuso el llamado sistema erasmiano (reformado, científico o nebrisense -eso último por Antonio de Nebrija-) al natural (nacional, histórico o reuchliniano - por Johann Reuchlin, el mayor opositor alemán a la teoría anterior en el siglo xvI-); eso sí, todos ellos referidos exclusivamente al dialecto ateniense (Erasmo no diferenció dialectos ni períodos), a fin de vislumbrar la falta de solidez científica de la corriente erasmiana, en tanto y cuando las diferencias de los valores fonéticos desde el siglo $\mathrm{v}$ a.C. en adelante que concurrían en Ática, o son mínimas o se alternan con la pronunciación natural.

La mayor controversia ha residido desde sus inicios en el modo de pronunciar la letra $<\mathrm{H}>$ (eta o ita, según qué sistema de pronunciación adoptemos) y, posiblemente, la que ha dado pie a la rivalidad dialéctica entre las dos partes, los Etazisten e Itazisten o Iotazisten en alemán (donde surgió el primer foco de controversias ya desde mediados del siglo XVI), es decir, etacistas e itacistas o iotacistas, pues la antigua eta, según Erasmo, se debía pronunciar, en base a las transliteraciones entre el

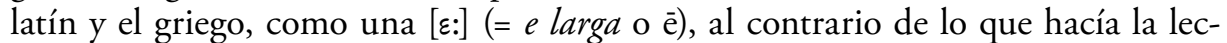
tura bizantina (= pronunciación natural), que la trata como una [i] ( $i$ breve o $)^{2}$. Sin embargo, está más que demostrado que a partir del s. va.C., incluso hay casos del s. VI, se daban ambas pronunciaciones. Además, el itacismo fue la norma a partir del período helenístico (Tovar 1990: 333-337; Caragounis 1995: 158-162). O dicho como lo hace ПeTpornias ( $\left.\beta 2002^{2} \alpha: 442\right)$ :

«El cambio de la vocal larga abierta [ $\varepsilon:] \quad\langle\eta\rangle$ a cerrada [e:] y finalmente en [i:] se completó en el dialecto ático del V siglo (en base a los continuos errores intercambiables en inscripciones y papiros) y se normalizó desde la época helenística».

De este fenómeno hay varios testimonios, siendo el pasaje más célebre un conocido texto del Crátilo (diálogo considerado por muchos el predecesor legítimo de la lingüística moderna, incluso del signo lingüístico de Saussure y compuesto por Platón en el 360 a.C. aproximadamente), en el que se refiere que la $\langle\eta\rangle$ [ع:] se pronunciaba [i] desde mucho antes de su época:

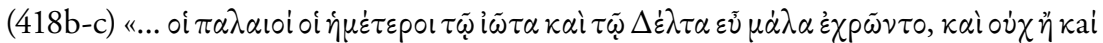

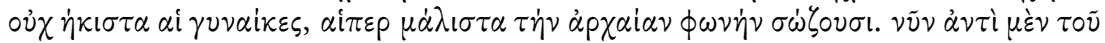

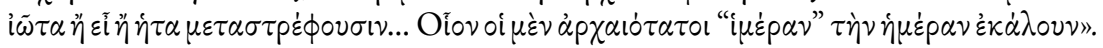


... nuestros antepasados usaban bastante la iota y la delta, y no menos las mujeres, las cuales mantienen la lengua antigua. Ahora, en vez de la iota, ponen عĩ o $\dot{\eta}$... Es decir, los más antiguos llamaban «iméran» a eméran.

El texto de Platón nos expone nítidamente cuál era la pronunciación de la $<\eta>$ en la época clásica, pero también mucho antes: los ảpxaı́o $\varepsilon p o$, los más antiguos (es de imaginar la época preclásica), la pronunciaban [i:] (probablemente larga), que se alternaba con la [в:], pero sobre todo las mujeres, más conservadoras en el uso la lengua (probablemente por su limitada socialización), la pronunciaban [i:]. Así pues, según Sócrates, que es el interlocutor en este diálogo, el iotacismo precede al etacismo, y/o ambas pronunciaciones se alternaban (Tovar 1990: 333-334) ${ }^{17}$.

Obviamente, ha habido una evolución fonética del griego a lo largo de los siglos. No obstante, esa movilidad en la evolución fonética es, precisamente, la razón de la necesidad de una sistematización de la expresión oral que proporcione cohesión y unidad al conjunto de la lengua. Y la única pronunciación aceptable es la que llevaron los bizantinos a Italia al inicio del Renacimiento, que es exactamente la misma que hoy en día se oye y se habla en Grecia y Chipre, aparte de en unas pocas zonas del sur de Italia y del oeste de Turquía.

La conclusión que deriva de todo lo expuesto previamente nos lleva a que nos hagamos algunas preguntas sobre la aplicabilidad y competencia del sistema propuesto por Erasmo.

¿Cómo pronunciar la [e:] larga cerrada de $\varepsilon i \mu i$ o $\lambda \varepsilon i \pi \omega$, si además sabemos que desde el principio de la época clásica el diptongo $<\varepsilon l>$ había monoptongado en [e:] coincidiendo con los alargamientos compensatorios y las contracciones de $\varepsilon+\varepsilon$, y que, más tarde, se pronunció como <l> larga [i:], en lo que acabó también la antigua vocal larga [e:], siendo que, en época helenística, ambos grafemas confluyeron en la pronunciación [i:] (ПETPOrNIA $2002^{2} \gamma$ : 445), aunque uno y otro han seguido escribiéndose $\langle\varepsilon l\rangle \mathrm{y}\langle\eta\rangle$, respectivamente? Pongamos solo un ejemplo representativo de lo que supondría una adopción rígida de la llamada pronunciación científica. Si siguiéramos la pronunciación erasmiana, el diptongo $<\varepsilon l>$ lo pronunciaríamos [ei] en las primeras tragedias de Esquilo, como [e:] en las de Sófocles y Eurípides, y probablemente como [i:] en las últimas obras de Isócrates, para pasar a pronunciarlo [i] breve desde el comediógrafo Menandro en adelante: sin lugar a dudas Menandro habría reunido material burlesco suficiente para defender, ante su público, la jocosidad que desataría esta cuestión lingüística.

Es evidente que ninguna de las dos opciones representa con fidelidad la pronunciación del griego preclásico o clásico, si bien la que se ha realizado desde el período helenístico en adelante (a la que se suma una extensa variedad de sonidos ya existentes desde inicios de época clásica, sobre todo en el dialecto ático) está ya ampliamente presente en la fonética del griego actual. Por tanto, si todos hicié-

17 El mismo fenómeno lo explican también Aristóteles, en su Ética Nicomaquea, y Dionisio de Halicarnaso, en Sobre la composición. 
ramos uso de la pronunciación del griego actual, nos sería más fácil reconocer que estamos leyendo y pronunciando in faciem terrae una misma lengua, mientras que con la pronunciación erasmiana tendremos que admitir versiones fragmentadas e incoherentes, pues la pronunciación «a la española» estaría tan justificada como la que se hace «a la inglesa»o «a la alemana» (Петpornias 2002² $\beta$ : 951-952) ${ }^{18}$. Y también será cierto que cuando escucháramos un texto griego distinto «a nuestra manera», no lo entenderíamos ni nos entenderían cuando lo leyéramos nosotros.

\section{CONCLUSIONES}

La insistencia en la idea de la oralidad como el principal atributo de la lengua a lo largo de nuestro trabajo se enmarca también en la necesidad de superar lo que, en principio, es una obviedad. Porque lo contrario de lo que, a nuestro entender, es obvio nos ha sido impuesto durante más de dos siglos en el mundo occidental, originado por la confusión entre hechos de lengua y de habla. Nos parece una obviedad que, al nivel abstracto del estudio de la lengua, sean precisadas puntualmente las observaciones de los valores fonéticos o informaciones punteras sobre el sistema fonológico que la investigación lingüística considere pertinentes. Sin embargo, creemos que es rebatible e ilícito que tales conclusiones sean aplicables a la forma hablada, tanto por su carácter hipotético como por la variabilidad de los tipos en la forma (variedades dialectales) y en el tiempo (evolución diacrónica).

Como ya hemos referido, no hay sistema lingüístico capaz de reproducir fielmente la pronunciación antigua, pero la importancia del griego actual reside principalmente en que su pronunciación es el corolario de la evolución natural de la forma lingüística antigua y, por seguir siendo el vehículo de comunicación hoy en día en Grecia, es para todos la vía más cercana y segura para acceder al griego clásico, la única forma sincrética y ecuménica.

Quisiéramos finalizar apostillando que la escritura nos ha traído la historia y la historia la escritura, del mismo modo que el habla es la esencia de la lengua y la lengua es esencia sublime del ser humano por su intencionalidad comunicativa inherente.

\section{ANEXO}

Algunos testimonios de lingüistas y literatos que defienden de manera acérrima la continuidad histórica e ininterrumpida de la lengua griega ${ }^{19}$.

${ }^{18}$ Cf. Caragounis (1995: 155): «... in actual practice Greek is pronounced in conformity to German, English, French and so on, according to the mother tongue of the speaker 6 (hence in our international New Testament conferences we are often conscious of a Babel-like experience when trying to figure out which Greek word the speaker was trying to pronounce)».

19 Los textos han sido traducidos por mí. 
1. इофокмнг, E.A. (apud Tovar 1990: 356 ${ }^{20}$ : «La lengua griega es una, con diversas formas, con su típica polimorfía, y la diferencia entre el griego de Aristóteles y Seferis es similar a la existente entre Shakespeare y Faulkner o entre Cervantes y Borges».

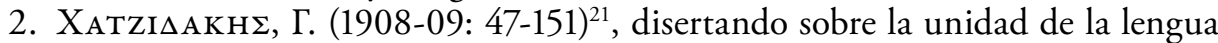
griega y sobre el hecho de que el ciudadano griego de hoy en día utiliza activamente o comprende infinidad de palabras que se usaban hace 2000 años, dice: «De las aproximadamente 4900 palabras del Nuevo Testamento casi la mitad se dicen todavía hoy, incluso en el habla cotidiana; de las restantes, la mayoría, 2220 palabras, se entienden bien y son reconocibles por todos los griegos, solamente unas pocas, alrededor de 400, son realmente incomprensibles para el pueblo griego».

3. इефернг, Г. (1962: 177)22: «La lengua griega, el hombre, el mar... Mirad lo sorprendente que es darse cuenta, desde la época en que habló Homero hasta hoy, de que hablamos, respiramos y cantamos en la misma lengua».

4. Eırthe, O. (Discurso de recepción del Premio Nobel en 1979) 23: «Me tocó escribir en una lengua que es hablada sólo por unos pocos millones de personas. Pese a eso, es una lengua que lleva hablándose dos mil quinientos años sin interrupción y con escasas diferencias. Esta dimensión aparentemente absurda se corresponde con la entidad espiritual y material de mi país. Que es pequeño en su extensión espacial e inmenso en su extensión temporal. $Y$ no lo digo en absoluto para enorgullecerme, sino para hacer notar las dificultades que afronta un poeta cuando emplea para las cosas más queridas, las mismas palabras que empleaban poetas tales como Safo y Píndaro».

5. BROWNING $\left(1982^{2}\right.$ : «Perhaps connected with this continuous identity over some three and a half millennia is the slowness of change in Greek. It is still recognizably the same language today as it was when the Homeric poems were written down, probably around 700 B.C., though it must be observed that the traditional orthography masks many of the phonetical changes which have taken place. The continuity of lexical stock is striking- though here too things are not as simple as they seem at first sight. And though there has been much rearrangement of morphological patterns, there has also been much continuity, and Greek is quite clearly even today an archaic, 'Indo-European' type of language, like Latin or Russian, not a modern, analytical language, like English or Persian».

${ }^{20}$ Célebre filólogo clásico de la segunda mitad del siglo XIX en Harvard.

${ }^{21}$ Giorgos Hatzidakis, reconocido como el lingüista más importante e influyente de finales del siglo xix y principios del xx, fue el primer catedrático de la Facultad de Filología de la Universidad de Atenas e introductor del estudio de la historia de la lengua griega en Grecia.

${ }_{22}$ Poeta. Premio Nobel de Literatura en 1963.

${ }^{23}$ Poeta. Doctor honoris causa por la Universidad de Tesalónica en 1978 y premio Nobel de literatura en 1979. 
6. Tonnet (1993: 18): «Le grec moderne n'est pas une langue entièrement nouvelle issue du grec ancien, il est la forme actuelle d'une langue qui n'est pas morte, le grec».

7. Мпампілі $\Omega$ Thг, Г. $(2002 \text {, p. } 14)^{24}$ : «El vocabulario del griego es un testigo irrefutable de la continuidad ininterrumpida de la lengua griega y de su carácter unitario. Ningún griego o extranjero (a excepción de los especialistas de la historia de la lengua griega) puede distinguir si una palabra actual es antigua, bizantina o reciente».

ReCibido: octubre de 2019; ACEPTADo: diciembre de 2019

${ }^{24}$ Yorgos Babiniotis es un renombrado lingüista griego. Ha sido profesor y rector de la Universidad de Atenas. Entre otras obras, destaca el último e importantísimo diccionario de la lengua griega, editado en 2002 con innumerables comentarios lingüísticos. 


\section{BIBLIOGRAFÍA}

Allen, Sidney W. $\left(1991^{3}\right)$ : Vox Graeca. A guide to the pronunciation of the classical Greek, Cambridge: Cambridge University Press.

Browning, R. (1982²): Medieval and Modern Greek, Cambridge: Cambridge University Press.

Caragounis, Ch. C. (1995): «The error of Erasmus and un-Greek Pronunciations of Greek», Filología Neotestamentaria, viII: 151-185.

Carbonell, Santiago (2010): La crisis del griego antiguo y los métodos antidepresivos, Alicante: Universidad de Alicante, http://www.culturaclasica.com/lingualatina/La-crisis-del-griego-ylos-metodos-antidepresivos.pdf.

Correa Morales, Ismael (2017-2018): «Epítome a propósito de la katharévusa», Fortunatae XxviII (volumen en homenaje a la memoria de Isabel García Gálvez): 47-56.

FaulKner, John Alfred (1907): Erasmus The Scholar, Cincinnati: Jennings and Graham.

Gardner, H. $\left(2107^{3}\right)$ : Estructuras de la mente. La teoria de las inteligencias múltiples, México: Fondo de Cultura Económica.

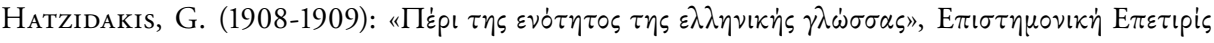

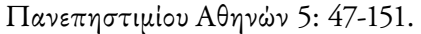

Horrocks, G. (1997): Greek. A history of the language and its speakers, NewYork: Longman.

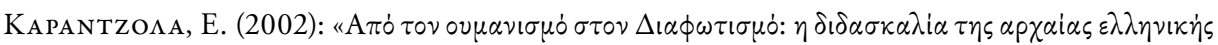

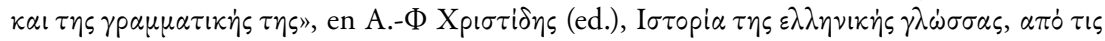

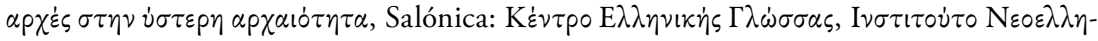

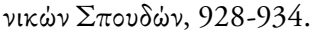

Lafaye, J. (2005): Por amor al griego. La nación europea, señorio humanista (siglos XIV-XVII), México: Fondo de Cultura Económica.

Lejeune, M. (1972): Phonétique historique du mycénien et du grec ancien, Paris: Klincksieck.

Luque Moreno, J. (2014): Hablar y cantar. La música en el lenguaje, Granada: Editorial Universidad de Granada.

Martínez Celdrán, E. (1996): El sonido en la comunicación humana. Introducción a la fonética, Barcelona: Ediciones Octaedro.

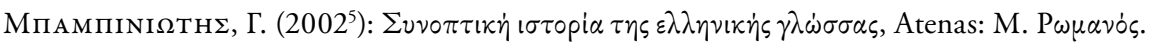

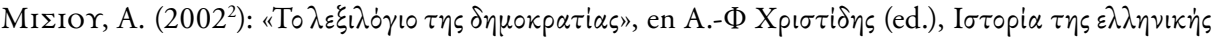

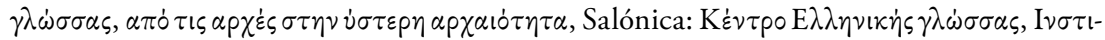
$\tau \circ \dot{\tau} \tau \circ \mathrm{N} \varepsilon \circ \varepsilon \lambda \lambda \eta \nu$ เ $\dot{\omega} \nu \sum \pi \circ \nu \delta \dot{\omega} \nu, 794-799$.

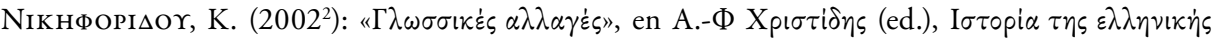

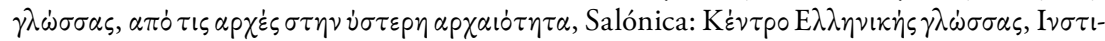

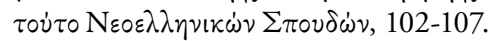

Ong, W.J. (1982): Oralidad y escritura, México: Fondo de Cultura Económica.

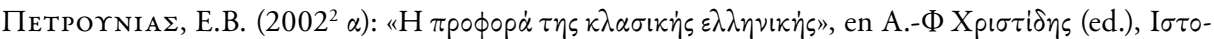

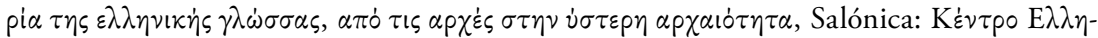

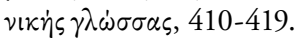




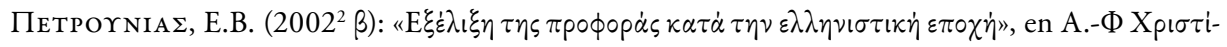

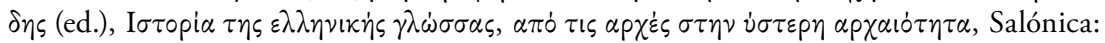

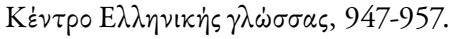

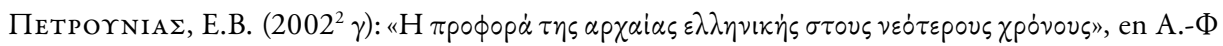

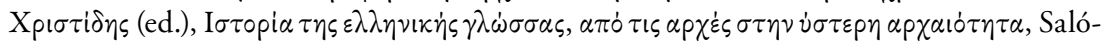

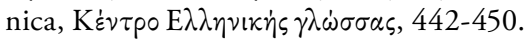

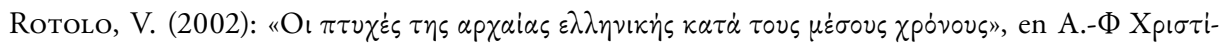

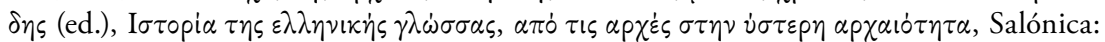

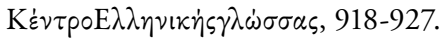

Ruiz Casanova, José Francisco (2018): Ensayo de una historia de la traducción en España, Madrid: Cátedra.

Saussure, Ferdinand de $\left(1945^{14}\right)$ : Curso de lingüistica general, Buenos Aires: Editorial Losada.

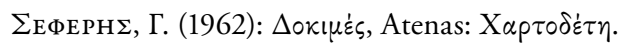

Signes Codoñer, J. (2003): «Translatio studiorum: la emigración bizantina a Europa Occidental en las décadas finales del imperio (1353-1453)», en Pedro Bádenas de la Peńa e Inmaculada Pérez Martín (eds.), Constantinopla 1453. Mitos y realidades, Madrid: CSIC,187-246.

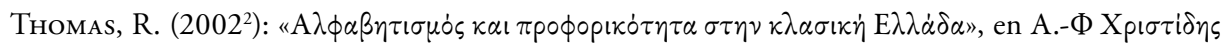

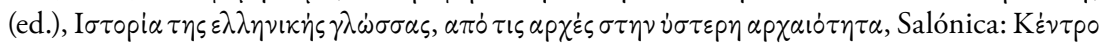
E $\lambda \lambda \eta \nu เ \kappa \eta \dot{~} \varsigma \gamma \lambda \omega \dot{\omega} \sigma \sigma \alpha \varsigma, 237-246$.

Tonnet, Henri (1993): Histoire du grec moderne: la formation d'une langue, Paris: L'Asiathèque.

Tovar, Saúl (1990): Biografía de la lengua griega. Sus 3000 años de continuidad, Santiago de Chile: Universidad de Chile. 